\title{
EL RECURSO DE QUEJA Y LA ORDEN DE NO INNOVAR A PROPÓSITO DEL CASO ATALA
}

\author{
Queja motion and no innovar order in the Atala's case
}

Juan Carlos Marín González.

\begin{abstract}
Resumen: El trabajo hace una crítica a la sentencia de la Corte Suprema que acogió un recurso de queja mediante el cual se entregó de manera definitiva la tuición de las hijas de Karen Atala al padre de las menores. En opinión del autor, la única razón por la cual la referida sentencia privó a la madre del cuidado de sus hijas se encuentra en su carácter homosexual. El fallo no solo es abiertamente discriminatorio por la razón apuntada, sino por haber utilizado un recurso no previsto para ello. A través del recurso de queja no podía alterarse la valoración de la prueba que era y es una facultad privativa de los jueces de instancia. Adicionalmente, se cuestiona la utilización abusiva de la orden de no innovar que en vez de haber mantenido el statu quo que favorecía a la madre, lo alteró dramáticamente impidiendo que las dos sentencias de instancia que habían rechazado la demanda de tuición del padre no pudieren cumplirse, manteniéndose, de ese modo, de manera artificial la tuición provisional de las niñas en la persona del padre.
\end{abstract}

Palabras clave: homosexualidad - discriminación - medidas provisionales - género.

Abstract: The article criticizes the Supreme Court's ruling by which it accepted a claim lodged through a Queja motion, granting the definite custody of Karen Atala's daughters to their father. In author's opinion, the only reason why the aforementioned ruling deprived the mother of the children's custody is due to her homosexuality. The decision is not only openly discriminatory because of the aforesaid cause, but for using the Queja motion, a motion which was not envisaged for that purpose. Through the Queja motion the Supreme Court was not allowed to alter de valuation of proof, for this power has always been granted in an exclusive manner to first instance judges. In addition, the author questions the abusive use of the no innovar order, which instead of maintaining the statu quo that favored the mother, altered it in a dramatic manner and impeded the fulfillment of the two former rulings which had rejected the custody claim lodged by the father, keeping, in an artificial way, the provisional custody of the children with the father.

Keywords: Homosexuality - discrimination - provisional remedies - gender.

\footnotetext{
* Doctor en Derecho. Profesor de tiempo completo en el Instituto Tecnológico Autónomo de México (ITAM). Investigador del Centro de Estudios de la Justicia. Facultad de Derecho. Universidad de Chile.

Correo electrónico: jcmarin@itam.mx
} 
Marín - El recurso de queja y la orden de no innovar a propósito del caso Atala

\section{Planteamiento}

El 31 de mayo de 2004 la Corte Suprema resolvió el recurso de queja rol 1.193-03 ordenando que la tuición de las hijas de doña Karen Atala Riffo se entregara al padre de las menores. Esta resolución de nuestro más alto tribunal provocó, luego de un largo proceso, que la Comisión Interamericana de Derechos Humanos demandara al Estado de Chile ante la Corte Interamericana de Derechos Humanos $(\mathrm{CIDH})$.

La aludida Corte declaró el 24 de febrero de 2012 responsable internacionalmente a Chile por haber vulnerado: i) el derecho a la igualdad y la no discriminación consagrado en el artículo 24 (igualdad ante la ley), en relación con el artículo 1.1 (obligación de respeto y garantía) de la Convención Americana, en perjuicio de Karen Atala Riffo; ii) el derecho a la igualdad y la no discriminación consagrado en el artículo 24 (igualdad ante la ley), en relación con los artículos 19 (derechos del niño) y 1.1. (obligación de respeto y garantía) de la Convención Americana, en perjuicio de las niñas M., V. y R.; iii) el derecho a la vida privada consagrado en el artículo 11.2 (protección a la honra y a la dignidad), en relación con el artículo 1.1. (obligación de respeto y garantía) de la Convención Americana, en perjuicio de Karen Atala Riffo; iv) los artículos 11.2 (protección a la honra y a la dignidad) y 17.1 (protección a la familia), en relación con el artículo 1.1 (obligación de respeto y garantía) de la Convención Americana en perjuicio de Karen Atala Riffo y de las niñas M., V. y R.; v) el derecho a ser oído consagrado en el artículo 8.1 (garantías judiciales), en relación con los artículos 19 (derechos del niño) y 1.1 (obligación de respeto y garantía) de la Convención Americana en perjuicio de las niñas M., V. y R., y vi) la garantía de imparcialidad consagrada en el artículo 8.1 (garantías judiciales), en relación con el artículo 1.1 (obligación de respeto y garantía) de la Convención Americana, respecto a la investigación disciplinaria, en perjuicio de Karen Atala Riffo.

Es bueno tener presente -así lo manifesté en la audiencia oral desarrollada en Santa Fe de Bogotá ante la Corte Interamericana de Derechos Humanos en mi calidad de experto en derecho procesal chileno- que el fallo de nuestra Corte Suprema no solo fue abiertamente discriminatorio en contra de doña Karen Atala Riffo en cuanto a su condición pública de homosexual y de conformar una nueva familia con una persona de su mismo sexo - esa fue la única razón por la cual ella perdió la tuición de sus hijas y esa fue la única razón por la cual el padre demandó dicha tuición ${ }^{1}-$, sino que avaló una serie de actuaciones altamente irregulares y

\footnotetext{
1 Véase, simplemente, el tono de la demanda de tuición: "Señala [la demanda] que, a la fecha, ambos cónyuges se encuentran separados de hecho, fundamentalmente por el reconocimiento expreso que la cónyuge, madre y demandada efectúa sobre su opción sexual, declarando abiertamente su lesbianismo. Añade [la demanda] que, las consecuencias y estragos ante esta nueva posición de la demandada, se comienzan rápidamente a sentir, [...] Expresa que, otro tanto se
} 
discriminatorias en contra de la madre de las menores, que incluyó una visita extraordinaria de un ministro de la Corte de Apelaciones de Temuco al juzgado penal en el que Karen Atala laboraba en Villarica.

No debe pasarse por alto que doña Karen Atala, en verdad, no perdió la tuición de sus hijas con el fallo de la Corte Suprema - como mañosamente más de alguien lo ha querido hacer ver-, sino desde el inicio mismo del proceso de tuición promovido por el padre con la concesión de una medida "provisional" anticipativa que alteró dramáticamente el statu quo existente antes de la demanda (por acuerdo de los padres al momento de su separación en mayo de 2002, y por ser la regla en nuestro ordenamiento jurídico, la tuición se entregó a la madre de las menores), medida anticipativa que fue mantenida de manera abusiva durante jtodo el proceso judicial pese a ser "provisional"! y existir ¡dos sentencias definitivas que dieron la razón a la madre! ${ }^{2}$

De allí la importancia del fallo de la CIDH: se conceda al Estado de Chile por haber permitido una serie de irregularidades y un largo proceso discriminatorio en contra de una madre homosexual chilena.

evidenció con la conducta de las menores, [...] , quienes no sólo afectadas por la separación de sus padres, y la ausencia de este último en la casa familiar, han sido espectadoras directas de esta nueva imagen asumida por la demandada, en la cual ejerciendo un rol absolutamente marital, trajo consigo a su pareja, [...], instalándola en el hogar común, asumiendo esta última el rol maternal con respecto a estas menores. Agrega que, desde la separación hasta la fecha, y con el objeto de que las menores no se sientan desamparadas, su representado las tiene bajo su cuidado prácticamente todos los fines de semana. Ello ha permitido constatar que sus hijas se encuentran en una situación de conflicto y competitividad respecto del cariño de su padre en forma muy dañina. La mayor [...] evade toda conversación que pueda involucrar las conductas de su madre; las dos menores por su parte, [...] manifiestan conductas notorias de masturbación. Asimismo, en el aspecto interno o sicológico, señala que hay situaciones que ameritan un llamado de alerta por el concepto distorsionado de familia que tienen las menores, producto de los mensajes que le transmite su ambiente familiar, y que las induce a una relación de competencia y agresividad con las figuras masculinas. [...]. Agrega, también, que en este contexto, y amparado por las normas de dicha Convención, las tres menores, de tan solo 8, 4 y 3 años, respectivamente, "no están siendo protegidas en su fin último que significa la protección a desarrollarse en un ambiente normal, que importe un equilibrio para su desarrollo emocional". Señalando que, a esto apunta la presente demanda, ya que la opción sexual ejercida por la madre altera esta convivencia sana, justa y normal a la que tienen derecho [las menores]".

${ }^{2}$ La historia no deja de ser veleidosa. Veo, ahora, en el Proyecto de Ley de nuevo Código Procesal Civil, recientemente enviado al Congreso Nacional por el actual Ejecutivo (que sustituye al enviado por la Presidenta Bachelet en mayo de 2009) que en la regulación de las medidas cautelares han desaparecido las anticipativas que sí preveía el proyecto de mayo de 2009. En la discusión de estos artículos quienes se opusieron tenazmente a la inclusión de medidas anticipativas en sede cautelar fueron los profesores Miguel Otero y José Pedro Silva, quienes nunca criticaron (el último incluso la defendió) la anomalía que aquí se relata. 
En el presente artículo criticaré el aludido fallo de la Corte Suprema y criticaré la manera como se utilizó la orden de no innovar durante el proceso de tuición de las menores, tanto por la Corte de Apelaciones de Temuco como por la propia Corte Suprema. No me referiré, por tanto en esta ocasión, a la resolución de la CIDH más allá de las referencias generales que ya he formulado.

Previamente, en todo caso, describiré brevemente la evolución que ha tenido el recurso de queja en nuestro sistema procesal, que muestra una constante peligrosa: el uso abusivo que de él hacen nuestros tribunales de justicia. Este último punto no es baladí: la Corte Suprema resolvió de la manera que lo hizo porque es lo que ordinariamente hace cuando utiliza el recurso de queja. ${ }^{3}$ Lo novedoso fue que ahora con el derecho internacional de los derechos humanos hay una Corte que puede revisar lo que antes no se revisaba.

\section{Reglas y principios legales sobre el recurso de queja}

\subsection{Reglamentación y origen del recurso de queja (1875-1943)}

La doctrina procesal chilena más calificada señala que el recurso de queja reconoce su fuente en el art. 82 de la Constitución Política (C. Pol.) que establece: "la Corte Suprema tiene la superintendencia directiva, correccional y económica de todos los tribunales de la nación. Se exceptúan de esta norma el Tribunal Constitucional, el Tribunal Calificador de Elecciones y los tribunales electorales regionales". ${ }^{4}$ Es en virtud de esta superintendencia correccional -se dice- que la Corte Suprema conoce del recurso de queja.

Si ello es correcto quiere decir que esta figura se enmarca dentro del ámbito de las prerrogativas disciplinarias de los tribunales superiores de justicia y no en el ámbito de sus facultades jurisdiccionales. Esto justificaría que no se encuentre prevista en el Código de Procedimiento Civil (CPC), ni figure entre los recursos que disponen las partes para impugnar una resolución judicial adversa. Su reglamentación, en el Código Orgánico de Tribunales (COT), es muy ejemplificativa al estar ubicado en el título XVI del COT De la jurisdicción disciplinaria y de la inspección y vigilancia de los servicios judiciales, a propósito de las facultades disciplinarias (arts. 535, 536, 541, 545, 548, 549 y 551).

\footnotetext{
3 Véase la temprana y lúcida crítica formulada a este fallo por Eduardo Court Murasso, "Familia", en Revista de Derecho de la Universidad Adolfo Ibánez, Nº 2 (2005), pp. 14-19.

${ }^{4}$ Mosquera Ruiz, Mario y Maturana Miquel, Cristián Los recursos procesales, $2^{\mathrm{a}}$ ed., Editorial Jurídica de Chile, 2012, p. 387.
} 
En verdad el origen de este recurso es jurisprudencial. ${ }^{5}$ En efecto, la Ley de Organización de los Tribunales del año 1875, en su art. 69, a propósito de las facultades de las Cortes de Apelaciones, previó la figura de la queja en los siguientes términos: "En virtud de la atribución de que habla el artículo anterior (mantener la disciplina en sus respectivas jurisdicciones) las Cortes de Apelaciones oirán y despacharán sumariamente y sin forma de juicio las quejas que las partes agraviadas interpusieren contra los jueces de letras por cualesquiera faltas o abusos que cometieren en el ejercicio de sus funciones; y dictarán, con previa audiencia del juez respectivo, las medidas convenientes para poner pronto remedio al mal que motivare la queja". El art. 109 de este ordenamiento procesal, por su parte, confería igual facultad a la Corte Suprema, respecto de cualesquiera jueces o funcionarios del orden judicial.

Como se aprecia, estábamos frente a una reclamación verbal que debía ser despachada sumariamente y sin forma de juicio, de manera que por la letra de la ley no podía aceptarse que diera lugar a una reclamación por escrito y que se tramitara a la manera de un juicio sumario. La queja no era un recurso debido a la profunda diferencia que existe entre aquélla y éstos. El recurso -en su acepción jurídica técnica- es un medio de defensa que tiene la parte agraviada por una resolución judicial para obtener su revisión y eventual revocación o modificación, por el propio tribunal que la emitió o por su superior jerárquico. En cambio la queja (al menos en su origen) nada tenía que ver con la reforma de resoluciones judiciales. Era un derecho que la ley reconocía a los litigantes para coadyuvar a la justicia en el deber de mantener su propia disciplina, y su objeto único e inmediato consistía en reprimir las faltas o abusos de los funcionarios judiciales.

Fueron los tribunales superiores de justicia en Chile, sin embargo, quienes desde muy temprano vieron en la figura regulada en el art. 69 del COT un verdadero recurso, ${ }^{6}$ y quienes, paulatinamente, entendieron que a través de este instrumento se podía, además de sancionar disciplinariamente a los jueces,

\footnotetext{
5 La Corte Suprema señaló que el recurso de queja nació mediante "una interpretación jurisprudencial que hicieron los tribunales superiores de los preceptos de la Ley de Organización y Atribuciones de los Tribunales de 1875, que instituyeron la queja como medio de corregir y sancionar las faltas o abusos en que hubieren podido incurrir los jueces en el ejercicio de su ministerio y si bien, con posterioridad el concepto de recurso de queja ha tenido acogida en la ley, no por ello ha perdido su carácter de recurso del que conoce el superior en ejercicio de sus facultades disciplinarias para modificar aquellas resoluciones en que los falladores, con errado concepto, se apartan del mérito del proceso y hacen mal uso de sus facultades en términos de producir al litigante un perjuicio que solamente puede ser reparado por este medio". RDJ, t. LXIII (1966), $2^{\text {a }}$ parte, sec. $3^{\text {a }}$, p. 117.

6 Véase al respecto la temprana jurisprudencia que cita Manuel Egidio Ballestero, en su monumental obra La ley de organización y atribuciones de los tribunales de Chile, t. I, Imprenta Nacional, Santiago, 1890, pp. 399 y 400.
} 
modificar resoluciones judiciales. Este fue un giro copernical en el entendimiento de esta figura procesal. ${ }^{7}$ Lo anterior, como no podía ser otra manera, marcó la fisonomía y derrotero de este recurso. De este modo, los jueces en Chile (particularmente los de la Corte Suprema) se acostumbraron a manejar este instrumento con enorme discrecionalidad, situación que, inclusive, los ha llevado en algunos casos a no sentirse vinculados por las modificaciones que el legislador a lo largo de los años ha introduciendo a esta figura procesal, ${ }^{8}$ o a imaginar facultades legales.'

La anterior evolución fue, en todo caso, un claro error. El recurso de queja no constituye un tercer grado de revisión del fallo de segunda instancia. El mismo no se interpone en contra de una resolución judicial, lo que es propio de los recursos propiamente tales, sino en contra de los jueces o ministros que con falta o abuso hubieren emitido una resolución jurisdiccional. Sobre este punto existe pleno consenso en la doctrina procesal chilena: "Es un recurso que se interpone no en contra de una resolución, sino en contra del juez o jueces que dictaron la resolución con falta o abuso grave, para que en caso de ser ella acreditada sea modificada, enmendada o dejada sin efecto a fin de poner pronto remedio al mal que motiva el recurso. Es un recurso que no ha sido instituido para corregir simples errores de interpretación, sino que faltas o abusos ministeriales de parte del sentenciador que caigan dentro del ámbito de la jurisdicción disciplinaria del superior jerárquico. Es un recurso que no constituye instancia para la revisión de todas las cuestiones de hecho y de derecho, sino que únicamente faculta al superior para examinar si se cometió la falta o abuso grave invocada por el recurrente". ${ }^{10}$

En verdad, este recurso siempre ha constituido una figura extraña en nuestro sistema procesal. Lo anterior, según lo hemos referido, debido a que su origen y razón de ser dicen relación con las facultades disciplinarias de nuestro

\footnotetext{
${ }^{7}$ Tal vez a esto contribuyó el que no se hubiere señalado a propósito de la regulación de la queja en la Ley de Organización y Atribuciones de los Tribunales de 1875, el que la misma no procedía en contra de resoluciones judiciales, como fue la intención primigenia de los autores de la ley. También el que no existiera en ese entonces el recurso de casación en el fondo. La Corte necesitaba un instrumento para hacer "justicia" en el caso concreto y encontró en esta figura una herramienta apropiada para ello.

${ }^{8}$ Véase, por ejemplo, sentencia de la Corte Suprema del 26 de junio de 1996 en la que declaró "la aplicación del citado inciso final del art. 545 del COT resulta, evidentemente violatorio del art. 79 de la Constitución Política de la República, por cuanto la expresada ley no puede disminuir las atribuciones constitucionales privativas de esta Corte o constriñendo su amplia facultad de imponer o no medidas disciplinarias en los supuestos de darse acogida a un recurso de queja".

9 C. fr. Atria, Fenando, "Proceso Civil. En ejercicio de la (imaginaria) facultad contenida en el artículo 545 del Código Orgánico de Tribunales", en Revista de Derecho de la Universidad Adolfo Ibánez, $\mathrm{N}^{\circ} 2$ (2005), pp. 345-349.

${ }^{10}$ Mosquera Ruiz, Mario y Maturana Miquel, Cristián: Los Recursos..., p. 390.
} 
máximo tribunal y no con sus facultades jurisdiccionales. La práctica judicial, como también lo hemos expresado, lo llevó por otro derrotero. ${ }^{11}$ Este derrotero fue al que el legislador nacional puso término el año 1995. Al menos esa fue su clara intención según lo veremos un poco más adelante.

\subsection{Situación del recurso de queja entre los años 1943-1995}

En el Código Orgánico de Tribunales, aprobado el año $1943,{ }^{12}$ se vino a patentizar el recurso de queja, en términos algo parecidos a lo que hemos visto fue la evolución jurisprudencial de la queja. ${ }^{13}$ La Corte Suprema en virtud de sus facultades económicas dictó, adicionalmente, sendos Autos Acordados (1963 y 1972) en los cuales reguló la tramitación tanto de la queja, como del recurso de queja. De este modo la original queja prevista en el art. 69 de la LOT de 1875, legalmente devino en dos instituciones diversas: la queja, prevista en el art. 536 y el recurso de queja, en el art. 545, ambos del COT.

Las críticas a esta regulación por parte de la doctrina procesal chilena no se hicieron esperar. Los autores de aquellos años denunciaban los enormes problemas que dicha reglamentación provocaba en el foro chileno. Carlos Anabalón S., uno de los procesalistas más finos que ha tenido el país, escribía a mediados del siglo pasado: "Pero, donde la confusión adquiere contornos de un mal endémico es en el conocimiento del Recurso de Queja que, siendo por su origen y naturaleza una simple facultad tendiente a remediar las faltas o abusos de

\footnotetext{
11 Tavolari ha reconocido al respecto que esta situación también encuentra su justificación en el "bajo nivel general de la ciencia jurídica chilena y de nosotros, sus operadores. Jueces y abogados buscamos la solución más simple, que evite, a unos y otros, los razonamientos jurídicos afinados y refinados. En el ámbito judicial, jueces y abogados nacionales trabajamos pues, en general, con la brocha gorda del obrero pintor antes que con el fino pincel del artista. En estas circunstancias no puede sorprender la simpatía que, a uno y otro lado de los estrados, se dispensa al recurso de queja”. Recurso de Casación y Queja, nuevo régimen, Editorial Cono Sur, 1996, pp. 6 y 7.

12 Por Decreto de 19 de agosto de 1942 se comisionó a la Facultad de Derecho de la Universidad de Chile para refundir en un solo texto la Ley de Organización y Atribuciones de los Tribunales de 1875, y todas las leyes que la habían modificado o complementado. Este trabajo dio origen al nuevo texto del Código Orgánico de Tribunales, sancionado por Ley $\mathrm{N}^{\circ} 7.421$ de 09 de julio de 1943.

${ }^{13}$ La Ley No 3.390, de 15 de julio de 1918, que modificó la Ley de Organización de los Tribunales y reformó diversos artículos del Código de Procedimiento Civil (CPC) fue, en todo caso, la primera que utilizó expresamente el nombre de recurso de queja. En efecto, el art. 16 señaló: "Los recursos de queja se verán por la Corte respectiva fuera de las horas ordinarias de audiencia. En las Cortes que consten de más de una sala, conocerá de estos recursos la sala en que funcione el presidente del tribunal y con asistencia de la mayoría de él".
} 
Marín - El recurso de queja y la orden de no innovar a propósito del caso Atala

los jueces en la tramitación y fallo de las causas, se ha convertido ya en una tercera instancia consagrada por el hábito". ${ }^{14}$

Sobre lo que sucedía en aquellos años en la práctica forense chilena, el referido autor nos comenta lo siguiente: "Sencillamente, que la Corte Suprema ha dado a la queja un alcance tan amplio e injustificado que en su interposición y concesión se cometen mayores abusos que aquel que se trata de remediar y ni siquiera se cumple, a veces, con la necesaria finalidad de la queja que no es otra que sancionar el abuso en la conducta ministerial de los jueces por medio de las medidas consignadas en el art. 537 del mismo COT, siempre que tal abuso no lo haya calificado la ley de crimen o simple delito". ${ }^{15}$

Comprender lo que sucedía con el recurso de queja en aquellos años es muy importante porque gran parte de los vicios que Anabalón denunciaba con singular dureza en su Tratado, son los mismos que, incluso, pese a la reforma del año 1995, nuestra Corte Suprema ha seguido cometiendo.

\subsection{Situación del recurso de queja después del año 1995}

Todos estos abusos y malas prácticas desarrolladas por nuestros tribunales superiores y, especialmente, por nuestra Corte Suprema, obligaron al legislador a intervenir a poco de haber retornado a la democracia. La Ley $\mathrm{N}^{\circ} 19.374$, de 18 de febrero de 1995, modificó radicalmente el recurso de queja. También introdujo importantes cambios al recurso de casación. En el mensaje que acompañó al proyecto de ley se expresó lo siguiente:

Las disposiciones de este proyecto de ley tienen por objeto promover una profunda modernización en el Poder judicial y, en especial, en su máximo tribunal, la Corte Suprema, tanto en su organización como en las materias y procedimientos que le incumben. (...). Por otra parte, se amplía el ámbito para interponer el Recurso de Casación y se restringe el del Recurso de Queja, con modificaciones a los artículos 767 y siguientes del Código de Procedimiento Civil, y a los artículos 545 y 549 del Código Orgánico de Tribunales, respectivamente. (...) El de queja se limita porque entendemos que, siendo éste un recurso disciplinario, ha distorsionado en la práctica el sistema procesal y la función jurisdiccional de los Tribunales Superiores de Justicia, toda vez que se interpone en vez de otros recursos procedentes, recargando el trabajo de las Cortes, dándose el caso que por esa vía

\footnotetext{
14 Anabalón Sanderson, Carlos: Tratado práctico de derecho procesal civil chileno, 2a . ed., Librotec Ltda., Concepción, 1966, p. 295. En el mismo sentido, C. fr. Tavolari Raúl, Recurso de Casación..., pp. 1 y 2. 15 Ibid, p. 298.
} 
la Corte Suprema pueda llegar a conocer de cualquier causa que se tramita en primera instancia. Estos recursos son fallados sin consignarse los fundamentos de las resoluciones y sin que sea escuchada la contraparte en el pleito, rompiéndose asi el principio de bilateralidad de la audiencia. ${ }^{16}$ (Énfasis añadido).

Fruto de esta reforma se modificó, tal cual se indicó en el mensaje, el artículo 545 del Código Orgánico de Tribunales (COT). La reforma de 1995 alteró la circunstancia que precisamente había permitido la proliferación de este recurso, disponiendo -entre otras importantes restricciones- que el recurso sólo procedería cuando la falta o abuso se cometa en una sentencia interlocutoria que ponga fin al juicio o haga imposible su continuación, o en una sentencia definitiva y que no sea susceptible de recurso alguno, ordinario o extraordinario.

Con todo, lo más importante de la reforma del año 1995 fue que puso término a la larga práctica desarrollada por nuestros tribunales superiores de justicia de considerar el recurso de queja como una tercera instancia. A partir de esta modificación legal quedaba sentado que los procesos jurisdiccionales civiles en Chile se desarrollaban en una doble instancia más un eventual recurso de casación. La costumbre de alterar los hechos y la valoración de la prueba por parte de la Corte Suprema conociendo del recurso de queja quedaba, normativamente, desterrada de su ámbito competencial. La propia Cuarta Sala de la Corte Suprema tuvo oportunidad de reconocer esta situación tan solo dos años después de haber fallado del recurso de queja que criticamos en este trabajo.

En apretada síntesis los hechos de este segundo proceso fueron los siguientes: frente a la petición de autorización de salida de una menor con su madre de Chile, el juez de primera instancia negó dicha autorización. La Corte de Apelaciones de Santiago, conociendo del recurso de apelación, revocó dicha resolución. El demandado, entonces, recurrió de queja en contra de los ministros integrantes de la Corte de Apelaciones de Santiago, don Carlos Cerda Fernández y doña Rosa María Maggi Ducommun, respectivamente, por estimar que procedieron con falta o abuso grave al revocar la sentencia de primera instancia. Frente a este recurso, nuestro máximo tribunal razonó en lo que ahora importa:

Que se debe, además, tener presente que la modificación introducida al recurso de queja por la Ley $\mathrm{N}^{\circ}$ 19.374, de 1.995, tuvo por objeto limitar este recurso disciplinario e impedir la distorsión del sistema procesal y de la función jurisdiccional de los tribunales superiores de justicia, con la finalidad de evitar su

\footnotetext{
16 Diario de sesiones del Senado, 12 de noviembre de 1992, sesión 10a ordinaria (anexo documentos), pp. 1015, 1016 y 1017.
} 
Marín - El recurso de queja y la orden de no innovar a propósito del caso Atala

práctica abusiva y, por ende, la revisión de juicios a través de una tercera instancia que no consultada en nuestro ordenamiento jurídico procesal vulneraba abiertamente el principio de la bilateralidad de la audiencia; (Énfasis añadido). Que, por lo anterior, no es extraño que la nueva normativa del Derecho de Familia lleve a excluir la posibilidad de recurrir por esta vía, privilegiando los recursos ordinarios y extraordinarios regulados en el Código de Procedimiento Civil, salvo modificaciones legales, pues el recurso de queja que describe el actual artículo 545 del Código Orgánico de Tribunales, es especialísimo y, fue contemplado en la ley con el exclusivo fin de corregir las faltas o abusos graves cometidos por los jueces en la dictación de resoluciones jurisdiccionales y de hacer efectiva la responsabilidad disciplinaria que por tal razón les asiste.

Por lo anterior, y teniendo presente que de lo expuesto con anterioridad se debe concluir que contra la sentencia definitiva de segunda instancia proceden sólo los recursos de casación en la forma y en el fondo, y por lo tanto el de queja resulta inadmisible, se rechaza el deducido en lo principal de fojas 10, contra la sentencia de dieciocho de abril de dos mil seis, escrita a fojas 234 , de los antecedentes tenidos a la vista. ${ }^{17}$

Como se aprecia, ahora, en materia de familia al preverse la existencia de recursos jurisdiccionales en contra de la sentencia de segunda instancia, la Corte entiende que el recurso de queja no es procedente. Lo importante es el reconocimiento expreso de la Corte Suprema en el sentido de con la reforma del año 1995 se había erradicado la distorsión que el recurso de queja había provocado en nuestro sistema procesal por la práctica abusiva - principalmente de la propia Corte dicho sea de paso- $y$, por ende, la revisión de juicios a través de una tercera instancia que no consultada en nuestro ordenamiento jurídico procesal vulneraba abiertamente el principio de la bilateralidad de la audiencia. Sin embargo, nada de esto sucedió dos años antes, ante el mismo tribunal.

\footnotetext{
${ }^{17}$ Recurso de Queja Rol No 1.735-06. Pronunciada por la Cuarta Sala de la Corte Suprema integrada por los Ministros señores José Luis Pérez Z., Orlando Álvarez H. y Urbano Marín V. y los Abogados Integrantes señores Roberto Jacob Ch. y Ricardo Peralta V.
} 
REJ - Revista de Estudios de la Justicia - No 15 - Año 2011

\section{Análisis particular del recurso de queja Rol $N^{\circ} 1.193-03$ fallado el 31 de mayo de 2004 por la Corte Suprema: breve referencia a las órdenes de no innovar concedidas}

\subsection{La orden de no innovar como forma de alterar el statu quo existente al momento de presentarse la demanda de tuición}

Para entender mejor esta situación es bueno conocer algunos hechos de la causa. En mayo de 2002 el matrimonio de las menores llegó a su fin. La tuición de las hijas quedó en manos de la madre con un régimen de visita del padre. En noviembre de ese año Karen Atala formó una nueva familia con una persona de su mismo sexo. En enero de 2003 el padre interpuso demanda de tuición en el juzgado de menores de Villarica. En marzo de ese año el padre pidió la tuición provisional de las menores. Esto equivale, para que nos entendamos, a pedir en un proceso reivindicatorio la entrega provisional del bien en disputa.

Por resolución de 2 de mayo de 2003 el juez titular de menores de Villarrica concedió la tuición provisoria de las niñas al padre y reguló las visitas de la madre. El juez justificó la medida a pesar de reconocer expresamente que no existían indicadores que permitieran presumir causales de inhabilidad legal de la madre que ameritaran el cambio de la tuición existente. ${ }^{18}$ Sin embargo, en su opinión, el hecho de que la madre hubiese explicitado su orientación homosexual y hubiera invitado a su pareja a compartir el hogar con sus hijas implicó que se alterara "la normalidad de la rutina familiar privilegiando sus intereses y bienestar personal por sobre el bienestar emocional y adecuado proceso de socialización de sus hijas a quienes en este aspecto no ha protegido debidamente". ${ }^{19} \mathrm{El}$ juez agregó en su resolución que el interés superior de las menores lo facultaba para considerar como causa justificada cualquier circunstancia que menoscabara la finalidad de procurar su máximo bienestar y estimó que un obstáculo para tal fin era que las niñas quedarían expuestas "en su medio a ser discriminadas". ${ }^{20}$ Concluyó el juez, en esa oportunidad, "[...] que esta forma es de estimarse de suficiente causa justificada el hecho cierto de que la demandada ha privilegiado su bienestar e interés personal por sobre el cumplimiento de su rol materno, en condiciones que pueden afectar el desarrollo posterior de las menores de autos y de lo cual no cabe sino concluir, que el actor presenta argumentos más favorables en pro del interés superior de las ninas, argumentos que en el contexto de una sociedad heterosexuada y tradicional cobran gran importancia". ${ }^{21}$

El 29 de octubre de 2003 la jueza subrogante del Juzgado de Letras de Villarrica dictó sentencia definitiva en el proceso de tuición negando la petición del

\footnotetext{
${ }^{18}$ Expediente de tuición provisoria, fojas 79.

${ }^{19}$ Expediente de tuición provisoria, fojas 79 .

${ }^{20}$ Expediente de tuición provisoria, fojas 79 vta.

${ }^{21}$ Expediente de tuición provisoria, fojas 80.
} 
padre. Esta resolución de primera instancia, en todo caso, no significó la reparación de los perjuicios que la resolución de tuición provisoria había ocasionado a Karen y sus hijas, porque ellas debieron seguir viviendo con su padre durante toda la duración de la apelación, en virtud de una orden de no innovar decretada por la Segunda Sala de la Corte de Apelaciones de Temuco con fecha 24 de noviembre del año 2003.

Con fecha 30 de marzo de 2004 la Corte de Apelaciones de Temuco confirmó por unanimidad la sentencia apelada. El día 5 de abril de 2004 el padre de las niñas presentó ante la Corte Suprema un recurso de queja en contra de los ministros de la Corte de Apelaciones de Temuco. El recurrente solicitó que se mantuviera provisoriamente a las niñas bajo el cuidado personal del padre, solicitud que fue acogida por la Corte Suprema al dictar una orden de no innovar, por resolución de fecha 7 de abril de 2004. El resto de la historia ya es conocido.

La gran paradoja, como ya lo habrá advertido el lector atento, es que la orden de no innovar en nuestro sistema procesal no sirven para mantener una innovación - quitar la tuición que la madre tenía de sus hijas- sino para mantener el statu quo, y el statu quo en este proceso era que la madre tenía el cuidado de sus hijas.

\subsection{El recurso de queja propiamente tal}

La Corte Suprema en su un fallo del año 2004 revocó las sentencias de segunda y primera instancias y de un plumazo hizo tabla rasa con toda la prueba rendida en dichas instancias. Debemos tener presente que este recurso de queja fue utilizado por nuestro más alto tribunal como una tercera instancia con un importante añadido: decidió alterar la valoración de la prueba en un proceso en que, por disposición legal, la misma se apreciaba en conciencia por los jueces. Así lo señalaba expresamente el art. 36 de la Ley de Menores: "El juez de letras de menores en todos los asuntos de que conozca apreciará la prueba en conciencia $[\ldots] "$.

Ahora bien, incluso en el evento que se sostuviera que la Corte por medio de este excepcional medio se encontraba facultada para alterar la apreciación en conciencia de la prueba de los jueces de instancia, no podría dejar de reconocerse que el fallo en cuestión es altamente discriminatorio por razón de género, y que esta fue la única causa que tuvo en vista la Corte para entregar la tuición de las hijas al padre y quitársela a la madre. No había ni riesgo ni daño alguno para las niñas que no fuera vivir en un entorno homosexual. La única razón por la cual se entregó la tuición al padre fue porque este ofrecía a las niñas una familia tradicional heterosexual. 
Analizaré estas dos situaciones por separado: (1) los considerandos donde se produce una clara alteración de la valoración de la prueba; y (2) los considerandos altamente discriminatorios por razón de género.

\subsubsection{Considerandos donde se produce la alteración de la prueba de instancia}

Antes de entrar en el análisis mismo del fallo en cuestión es bueno tener presente el único motivo que normativamente habilita al tribunal a cambiar la tuición de las hijas que, no lo olvidemos, corresponde por regla general a la madre en Chile, se prevé en el inciso $3^{\circ}$ del art. 225 del CC, referido al hecho de que el interés del hijo lo haga indispensable, fuere por maltrato, descuido u otra causa calificada. En la especie, según se acreditó en las respectivas sentencias de instancias, no eran aplicables ni el maltrato, ni el descuido de la madre, causales no probadas en autos. La única posibilidad que le quedaba a la Corte, entonces, era analizar la causal genérica prevista en la expresión "otra causa calificada". Señala el tribunal en su búsqueda de la causa habilitante:

Que, en consecuencia, el tribunal puede confiar el cuidado personal de los hijos al otro padre, haciendo cesar la tuición de quien la ejerce, si existe una causa calificada que haga indispensable adoptar la resolución, siempre teniendo en cuenta el interés del hijo (C. 12).

Para encontrar esta causa normativa la Corte se ve forzada a alterar la valoración de la prueba rendida en las respectivas instancias. La Corte inicia su construcción en el considerando décimo tercero:

Que la situación planteada en los autos en que se ha entablado el presente recurso de queja, revela que los jueces recurridos no consideraron debidamente los efectos que ella puede acarrear en el cabal resguardo de los intereses de las hijas y cometieron falta o abuso grave tanto al aplicar las normas legales que rigen la materia, como al apreciar los antecedentes de la causa en que pronunciaron la sentencia que ha originado el recurso (Énfasis añadido).

La expresión "[...] revela que los jueces recurridos no consideraron debidamente los efectos que ella puede acarrear en el cabal resguardo de los intereses de las hijas [...]" no es fácil de entender. Fuere como fuere, lo interesante es que en opinión de la Corte aquí se ha cometido la falta o abuso grave, y ello es así, tanto al aplicar las normas legales que se ocupan de la materia, como al apreciar los antecedentes de la causa. 
Marín - El recurso de queja y la orden de no innovar a propósito del caso Atala

De este considerando uno esperaría que la Corte hubiese mostrado cómo se producía la falta o abuso grave al aplicar las normas legales, cuestión que no sucede. La Corte concentra su argumentación en la apreciación de los antecedentes de la causa.

La clave de su razonamiento la encontramos en el considerando décimo quinto, donde entra derechamente a valorar la prueba rendida en autos. Prueba, ya lo hemos dicho, que se apreciaba en conciencia por los tribunales de instancia según lo disponía el hoy derogado art. 36 de la Ley de Menores. Valoración que, lógicamente, le estaba vedada alterar a nuestra Corte en un Recurso de Queja que, una vez más, no es un recurso jurisdiccional ni es instancia, tal cual, por lo demás, lo señaló el voto de minoría de este mismo fallo:

Que en el juicio de tuición de las menores López Atala se hizo valer la opinión de diferentes psicólogos y asistentes sociales acerca de que la condición de homosexual de la madre no vulneraría los derechos de sus hijas, ni la privaría de ejercer sus derechos de madre, pues se trata de una persona normal desde el punto de vista psicológico y psiquiátrico. En cambio, se ha prescindido de la prueba testimonial, producida tanto en el expediente de tuición definitiva como del cuaderno de tuición provisoria, que se han tenido a la vista, respecto al deterioro experimentado por el entorno social, familiar y educacional en que se desenvuelve la existencia de las menores, desde que la madre empezó a convivir en el hogar con su pareja homosexual y a que las niñas podrían ser objeto de discriminación social derivada de este hecho, pues las visitas de sus amigas al hogar común han disminuido y casi han cesado de un año a otro. Por su parte, el testimonio de personas cercanas a las menores, como son las empleadas de la casa, hacen referencia a juegos y actitudes de las niñas demostrativas de confusión ante la sexualidad materna que no han podido menos que percibir en la convivencia en el hogar con su nueva pareja (Énfasis añadido). (C. 15).

Es evidente como la Corte entiende que tiene competencia para analizar la prueba rendida en autos. En su opinión, si bien la prueba pericial sicológica fue bien apreciada por los juzgadores de instancia, no sucede lo mismo con la prueba testimonial que la Corte valora con especial énfasis. Sobra decir que en el proceso sobre tuición definitiva había abundante prueba testimonial en contra de la que selectivamente toma la Corte. Lo importante, en todo caso, es que esto no lo podía hacer nuestro tribunal. No tenía ni tiene competencia para ello. Sobre este punto existe en Chile una sólida jurisprudencia a propósito del recurso de casación en el 
fondo. Veamos, simplemente, algunos ejemplos de lo dicho por la propia Corte Suprema a este respecto:

En lo relativo a la vulneración de los artículos 384 y 408 del Código de Procedimiento Civil, resulta pertinente reiterar lo expresado por esta Corte, en el sentido que la aplicación de la primera de dichas normas, esto es, la apreciación de la prueba de testigos, no es susceptible de ser denunciada su infracción por medio del recurso de casación en el fondo, dado que esta labor es privativa de los jueces de la instancia, circunstancia que quedó de manifiesto en la historia fidedigna de su establecimiento al interior de la Comisión Revisora del Proyecto de Código de Procedimiento Civil, que consideró la disposición sólo como principios generales dados a los jueces, circunstancia que precisaría luego en la Comisión Mixta el senador Ballesteros, quien expuso que "deberá dejarse amplia libertad al tribunal para apreciar el mérito probatorio de las declaraciones de testigos, como quiera que en realidad constituyen sólo una presunción, en el sentido lato de la palabra. (C. Suprema, sentencia de 27 de julio de 2006, RDJ, t. CIII, sec. $1^{\text {a }}$, p. 591$)$.

En cuanto a la infracción del $\mathrm{N}^{\circ} 2$ del artículo 384 del Código de Procedimiento Civil en que el ejecutado sustenta también su recurso, la jurisprudencia uniforme de esta Corte ha señalado que son los jueces de la instancia los llamados a apreciar soberanamente el mérito de las declaraciones de testigos, conforme a las reglas que señala el artículo 384 citado y que cualquier apreciación de este mérito que hagan al respecto no puede generar una infracción de todas las leyes reguladoras de la prueba. Teniendo en consideración que el precepto en estudio utiliza una forma verbal facultativa, pues dispone que las declaraciones de dos o más testigos contestes en el hecho y en sus circunstancias esenciales, sin tachas, legalmente examinados y que den razón de sus dichos, podrá constituir prueba plena cuando no haya sido desvirtuada por otra prueba en contrario, no cabe sino concluir que los jueces del mérito, al ponderar los testimonios de quienes depusieron como testigos, ejercitan facultades privativas de su jurisdicción que, por lo mismo, no quedan sujetas al control que ejerce esta Corte de Casación. (C. Suprema, sentencia de 13 de julio de 2006, RDJ, t. CIII, sec. $1^{\text {a }}$, p. 575).

En ese contexto, el recurso estimó violentado, en primer lugar, el artículo 384 N $^{\circ} 2$ del Código de Procedimiento Civil; sin embargo, 
Marín - El recurso de queja y la orden de no innovar a propósito del caso Atala

esta es una disposición que no tiene el carácter de norma reguladora de la prueba que establezca parámetros legales fijos o determinados de apreciación, ya que deja entregada a los jueces del fondo la ponderación de la testifical, que debe analizarse comparativamente, esto es, en relación con los demás medios probatorios. Así, se trata de una norma que establece la apreciación judicial de los medios de convicción. En efecto, el precepto señala que "Los tribunales apreciarán la fuerza probatoria de los testigos conforme a las reglas siguientes": que entrega en número de 6 y el número 2 estatuye que: "La de dos o más testigos contestes en el hecho y en sus circunstancias esenciales, sin tacha, legalmente examinados y que den razón de sus dichos, podrá constituir plena prueba cuando no haya sido desvirtuada por otra prueba en contrario". Como se ve, el uso de la forma verbal "podrá" denota con claridad que no se trata de una norma obligatoria, que conduzca a los jueces por un canal interpretativo determinado. Además, agrega que podrá constituir plena prueba cuando no haya sido desvirtuada por otra prueba en contrario, lo que constituye una circunstancia que lógicamente deben analizar los jueces del fondo, recurriendo para ello a la labor de comparación de los diversos medios con que se cuente, conforme además al artículo 428 del mismo texto legal.

De acuerdo con lo dicho, siendo facultad privativa de los jueces referidos la ponderación de los medios de convicción, no pueden infringir la ley al hacerlo, sino que, por el contrario, así cumplen cabalmente con su deber legal, lo que lógicamente implica que deben llevar a cabo una labor intelectual que les resulta propia e íntima, lo que no se les puede reprochar salvo que se vulneraren normas del tipo indicado, lo que no es el caso de autos. (C. Suprema, rol 1784 de 2003, sentencia de 20 de enero de 2004).

Como se puede apreciar, la Corte Suprema tiene una consolidada jurisprudencia en torno a que la apreciación de la prueba testimonial y pericial queda soberanamente entregada a los jueces de instancia. Incluso, esto debe destacarse, la Corte ha efectuado esta construcción a propósito en un sistema en el que aún rige la prueba legal o tasada, como lo es el previsto en los artículos del CPC aplicables en estos fallos. Debemos destacar, nuevamente, que en materia de familia lo anterior se ve fuertemente reforzado al regir en este ámbito un sistema que da aún más libertad al juez para valorar dicha prueba: la apreciación en conciencia. 
REJ - Revista de Estudios de la Justicia - No 15 - Año 2011

\subsubsection{Considerandos altamente discriminatorios por razón de género}

Independiente de la opinión que se tenga en relación con la valoración de la prueba que hemos desarrollado precedentemente, la Corte en su fallo ha redactado considerandos que en $\mathrm{mi}$ concepto son fuertemente discriminatorios e, intolerables, para cualquiera persona sensible en este ámbito.

Refiere en el considerando décimo sexto:

Que, en el mismo orden de consideraciones, no es posible desconocer que la madre de las menores de autos, al tomar la decisión de explicitar su condición homosexual, como puede hacerlo libremente toda persona en el ámbito de sus derechos personalísimos en el género sexual, sin merecer por ello reprobación o reproche jurídico alguno, ba antepuesto sus propios intereses, postergando los de sus hijas, especialmente al iniciar una convivencia con su pareja homosexual en el mismo hogar en que lleva a efecto la crianza y cuidado de sus hijas separadamente del padre de éstas (Énfasis añadido). (C. 16).

Resulta palmario, de una nitidez que incluso asusta, que la Corte justifica su decisión de quitar la tuición de las hijas a su madre única y exclusivamente por la condición de homosexualidad de ésta, que sólo debe quedar en el ámbito de sus derechos personalísimos (¿intimidad?, ¿privacidad?) pero jamás en el ámbito familiar, donde se impone la familia "tradicional" chilena. Los dos considerandos que siguen discurren en la misma sintonía:

Que, aparte de los efectos que esa convivencia puede causar en el bienestar y desarrollo psíquico y emocional de las hijas, atendida sus edades, la eventual confusión de roles sexuales que puede producírseles por la carencia en el hogar de un padre de sexo masculino y su reemplazo por otra persona del género femenino, configura una situación de riesgo para el desarrollo integral de las menores respecto de la cual deben ser protegidas (Énfasis añadido). (C. 17).

Que, por otro lado, fuerza es admitir que dicha situación situará a las menores López Atala a un estado de vulnerabilidad en su medio social, pues es evidente que su entorno familiar excepcional se diferencia significativamente del que tienen sus compañeros de colegios y relaciones de la vecindad en que habitan, exponiéndolas a ser objeto de aislamiento y discriminación que igualmente afectará a su desarrollo personal (Énfasis añadido). (C. 18). 
Marín - El recurso de queja y la orden de no innovar a propósito del caso Atala

Es evidente que la situación de riesgo que la Corte desea evitar, el potencial daño que las niñas pueden padecer se produce por vivir en un ambiente homosexual. Esto es lo que resulta intolerable para la Corte, porque esta confusión de roles se produce por la carencia en el hogar de un padre de sexo masculino, lo que conlleva un entorno familiar excepcional, que diferenciará significativamente a las niñas del resto de sus compañeras y vecinas.

Que las condiciones descritas constituyen ampliamente la "causa calificada" que el legislador ha incluido entre las circunstancias que en conformidad con el artículo 225 del Código Civil, autorizan al juez para entregar el cuidado personal de los hijos al padre en lugar de la madre, pues ellas configuran un cuadro que irroga el riesgo de daños, los que podrían tornarse irreversibles, para los intereses de las menores, cuya protección debe preferir a toda otra consideración, en los términos definidos imperativamente por la normativa que gobierna la materia (Énfasis añadido). (C. 19).

Finalmente, la Corte ha encontrado la causa justificada que la "habilitaba" para entregar el cuidado personal de las hijas al padre en lugar de la madre. Aquél ofrecía como alternativa no mejores condiciones de vida para las niñas, no más cuidado ni cariño, sino un entorno familiar heterosexual. Todo lo anterior de conformidad con el modelo de la familia tradicional chilena, que nuestra Corte Suprema se ve obligada a defender:

Que al no haberlo estimado así los jueces recurridos, por no haber apreciado estrictamente en conciencia los antecedentes probatorios del proceso y haber preterido el derecho preferente de las menores a vivir y desarrollarse en el seno de una familia estructurada normalmente y apreciada en el medio social, según el modelo tradicional que le es propio, $\underline{\text { han }}$ incurrido en falta o abuso grave, que debe ser corregido por la vía de acoger el presente recurso de queja (Énfasis añadido). (C. 20).

Uno se pregunta, entonces, ¿cuál fue en definitiva la falta o abuso grave en que incurrieron los sentenciadores de instancia? Pareciera que su única falta o abuso grave fue haber apreciado en conciencia la prueba rendida en autos y no haber concluido de la misma que la condición de homosexual de la madre constituía un peligro para sus hijas, como lo entiende la Corte Suprema.

En mi concepto, el fallo de nuestra Corte Suprema es triplemente erróneo. (i) Lo es en primer lugar porque validó una situación legalmente insostenible: mantener una medida cautelar anticipativa (tuición provisional de las hijas 
REJ - Revista de Estudios de la Justicia - No 15 - Año 2011

entregadas al padre de las niñas con clara alteración del statu quo existente) en contra de dos sentencias definitivas de instancia. Esto no había sucedido antes en el foro chileno. Lo paradójico de esta anomalía fue que ello se consiguió mediante sendas órdenes de no innovar, que tienen como propósito evitar la alteración del statu quo y no confirmar su modificación; (ii) En segundo lugar, porque la Corte Suprema volvió a utilizar el recurso de queja como una tercera instancia para, de este modo, cuestionar y alterar la forma como los jueces habían apreciado la prueba rendida en autos. Apreciación que de conformidad con la Ley de Menores quedaba entregada a la conciencia del juzgador de instancia; (iii) Finalmente, porque el fallo es profundamente discriminatorio por razón de género. La única razón por la cual se concedió la tuición provisional y definitiva de las hijas al padre fue por el carácter homosexual de la madre, y por lo que ello iba a significar para las niñas, alejadas, de este modo, del modelo tradicional de familia chilena heterosexual que el padre ofrecía. Esta situación fue, simplemente, intolerable para nuestro máximo tribunal de justicia. 
Marín - El recurso de queja y la orden de no innovar a propósito del caso Atala

\section{BIBLIOGRAFÍA}

* ANABALÓN SANDERSON, Carlos: Tratado práctico de derecho procesal civil chileno, $2^{\mathrm{a}}$ ed., Librotec Ltda., Concepción, 1966.

* ATRIA LEMAitRE, Fernando: "Proceso Civil. En ejercicio de la (imaginaria) facultad contenida en el artículo 545 del Código Orgánico de Tribunales”, en Revista de Derecho de la Universidad Adolfo Ibánez, $\mathrm{N}^{\circ} 2$ (2005).

* BALLESTERO RÍOS, Manuel Egidio: La ley de organización y atribuciones de los tribunales de Chile, t. I, Imprenta Nacional, Santiago, 1890.

* COURT MURASSO, Eduardo: "Familia", en Revista de Derecho de la Universidad Adolfo Ibáñez, N² (2005).

* MOSQUERA RUIZ, Mario y MATURANA MIQUEL, Cristián: Los recursos procesales, $2^{\mathrm{a}}$ ed., Editorial Jurídica de Chile, 2012.

* TAvolari Oliveros, Raúl: Recurso de Casación y Queja, nuevo régimen, Editorial Cono Sur, 1996. 